\title{
Psicologia da Literatura e Psicologia na Literatura
}

Rosemary Conceição dos Santos ${ }^{1, *}$

Orcid.org/0000-0001-7304-0511

João Camilo dos Santos ${ }^{2}$

Orcid.org/0000-0001-9967-9946

José Aparecido da Silva ${ }^{3}$

Orcid.org/0000-0002-1852-369X

\author{
${ }^{1}$ Universidade de São Paulo, São Paulo, Brasil \\ ${ }^{2}$ University of California, Santa Bárbara, EUA \\ ${ }^{3}$ Universidade de São Paulo, Ribeirão Preto, Brasil
}

\section{Resumo}

Este trabalho efetua a leitura da relação temática que se estabelece entre Psicologia e Literatura em duas perspectivas: através das considerações estabelecidas nos Estudos Literários por René Wellek e Austin Warren (Psicologia da Literatura) e nos Estudos Psicológicos por Dante Moreira Leite (Psicologia na Literatura). Na primeira, ocupa-se do estudo psicológico do escritor como tipo ou indivíduo e dos tipos e das leis presentes em obras literárias; na segunda, da Psicologia como perspectiva para a recepção da Literatura, do processo criador, da análise psicológica do texto e das relações do leitor com seu público. O artigo apresenta os resultados parciais obtidos com o desenvolvimento da pesquisa bibliográfica necessária ao curso denominado Psicologia da Literatura e Psicologia na Literatura, ministrado na 43ㄹ Reunião Anual da Sociedade Brasileira de Psicologia, em Aracaju (Sergipe), em 2013. Apresenta, também, a esquematização detalhada do processo de leitura observada no processo de recepção textual e na interação organismo-ambiente.

Palavras-chave: Psicologia e Literatura, interdisciplinaridade, perspectiva.

\section{Psychology of Literature and Literature in Psychology}

\begin{abstract}
This paper performs the reading the thematic relationship established between Psychology and Literature in two perspectives: through the considerations set out in Literary Studies by René Wellek and Austin Warren (Psychology of Literature) and Psychological Studies by Dante Moreira Leite (Psychology in Literature). The first one deals with the psychological study of the writer as an individual and the type or types and laws present in literary works, in the second, psychology as a perspective for the teaching of literature, the creative process, the psychological analysis of text and reader relationships with your audience. $\mathrm{O}$ article presents the partial results obtained from the development of literature necessary to
\end{abstract}

* Endereço para correspondência: Universidade de São Paulo, Faculdade de Filosofia Letras e Ciências Humanas, Av. Prof. Luciano Gualberto, 403, Butantã, São Paulo, SP, Brasil 05508-900. Fone: (16) 99786-4788. E-mail: cienciausp@usp.br 
the course called the Psychology of Literature and Psychology in Literature, taught at the 43rd Annual Meeting of the Society of Psychologists in Aracaju (Sergipe), in 2013. It also presents the detailed schematization of the reading process observed in the textual reception process and in the organismenvironment interaction.

Keywords: Literature and Psychology, interdisciplinary, perspective.

\section{Psicología de la Literatura y Literatura en Psicología}

\section{Resumen}

En este trabajo se realiza la lectura de la relación temática que se establece entre la psicología y la literatura en dos perspectivas: através de las consideraciones expuestas en Estudios Literarios de René Wellek y Austin Warren (Psicología de la Literatura) y Estudios Psicológicos de Dante Moreira Leite (Psicología de Literatura). La primera se ocupa del estudio psicológico del escritor como un individuo y el tipo o los tipos y las leyes actuales sobre las obras literarias, en el segundo, la psicología como una perspectiva para la enseñanza de la literatura, el proceso creativo, el análisis psicológico de texto y relaciones del lector con su público. O artículo presenta los resultados parciales obtenidos en el desarrollo de la literatura necesaria para el curso llamada la Psicología de la Literatura y Psicología en literatura, ha enseñado en la 43 ${ }^{\text {a }}$ Reunión anual de la Sociedad de Psicólogos en Aracaju (Sergipe), en 2013. Se presenta, también, la esquematización detallada del proceso de lectura observada en el proceso de recepción textual y en la interacción organismo-ambiente.

Palabras clave: Literatura y Psicología, interdisciplinarios, perspectiva.

\section{Psicologia e Literatura: Uma Relação Interdisciplinar}

Entendendo a interdisciplinaridade como a proximidade que campos de conhecimento estabelecem uns com os outros, visando a ultrapassar os próprios princípios discursivos na intersecção com as perspectivas teóricas e modos de funcionamento deste(s) último(s), verifica-se que a mesma é oportuna no rompimento do caráter especializado das disciplinas, rompimento, este, verificável em diferentes níveis e graus (Pombo, 2005). Tal oportunidade, fique claro, sem desmerecer nenhum dos avanços que o estudo interdisciplinar possibilitou à humanidade, mas, sim, tentando reverter a situação de o homem moderno, a saber, o especialista, entender cada vez mais sobre cada vez menos, em especial na contemporaneidade, época em que, de modo geral, as novas mídias de acesso aberto disponibilizaram a todos, indistintamente, o conhecimento mundial a um simples toque em tela de cristal líquido. Neste contexto, que proximidade a Psicologia, ocupada com especificidades como conhecer, e interpretar, o ser humano, e o mundo, mantém com a Literatura, ocupada com a possibilidade de a imaginação desvincular-se de regras?

A Psicologia preza pela lógica, situação, esta, que se opõe, substancialmente, à Literatu$\mathrm{ra}$, ainda que esta seja alicerçada na verossimilhança. Nas palavras de Russell (1964, p. 551), "Psicólogos preferem observações que podem ser replicadas, enquanto o escritor sério lida com analogia, metáfora, e ambiguidade talvez intencional". Entretanto, a despeito disso, ambas apresentam em comum compreender o desenvolvimento de seus sujeitos, reais / personagens ficcionais, respectivamente, através dos conflitos e problemas que estes apresentam seja na vida, seja no enredo. Qualidade que leva, ainda segundo Russell, ao fato de o conhecimento de um campo poder contribuir para com outro, fazendo com que as preocupações de ambos possam ser descritas em, pelo menos, quatro categorias: a psicologia do escritor, a psicologia do processo criativo, o estudo do comportamento e as respostas à literatura. 
$\mathrm{Na}$ psicologia do escritor, a interpretação psicológica de biografias e autobiografias de escritores encontra-se presente auxiliando o conhecimento do autor e do ambiente em que este se encontra. Por sua vez, a psicologia do processo criativo foca tanto as personalidades do escritor e de suas personagens quanto a forma como estes funcionam, ou seja, se são corrigidos, reescritos e reelaborados de acordo com a alteração do modo de ser de seu criador. Estudos psicológicos do processo de criação de obras literárias acusam, de modo geral, as etapas que todo processo criativo desenvolve, respeitadas as variações de estilo peculiares a cada autor. Nesse contexto, o estudo do comportamento descrito busca, alicerçado na lógica psicológica, delinear o caráter e o registro de atitudes que o sujeito humano explicita, ou deixa subentendidas, ao realizá-las. De modo similar, também os leitores respondem, a seu modo, ao que leem, o que faz, das respostas à literatura, "efeitos" que determinados enredos comunicam aos leitores.

Interdisciplinarmente, a Psicologia, tal qual ocorre na perspectiva das disciplinas que lhe são afins, como é o caso da História, da Linguística, da Comunicação, das Ciências Sociais, da Filosofia, da Educação e das Artes (Artes Plásticas, Música, Teatro, Cinema), entre outras, na tentativa de estabelecer o grau de relação entre a obra de arte e o que a circunda, visando ao esclarecimento humano, permite o estudo extrínseco da literatura, ou seja, o estudo cuja perspectiva ou foco não estão voltados à essência literária, mas, sim, a um ponto externo desta, através do qual ela é contextualizada e interpretada. Nesta empreitada, estudiosos do assunto, a saber, Leite (2003) e Wellek e Warren (1949), na tentativa de contribuir na compreensão desta relação, buscaram esclarecer de que trata a relação psicologia e literatura expondo seu alcance e suas fragilidades.

Em René Wellek e Austin Warren (1949, p. 95), a expressão "psicologia da literatura" é definida como sendo (a) o estudo psicológico do escritor como tipo e indivíduo, (b) o estudo do processo de criação, (c) o estudo dos tipos e das leis que estão presentes nas obras literárias e (d) o estudo dos efeitos da literatura sobre os leitores. Para esses autores, estudar psicologicamente o escritor como indivíduo e tipo, bem como, seu processo de criação são ações que interessam à Psicologia da Arte, área da Psicologia que descreve e explica a experiência psicológica do ser nos comportamentos relacionados com a arte, seja apreciando-a, criando-a e executando-a, seja interagindo com o público e ouvindo-lhe as críticas.

\section{Psicologia da Literatura}

\section{O Estudo Psicológico do Escritor como Tipo e Indivíduo}

O estudo de como as pessoas pensam, agem, influenciam e se relacionam cabe ao contexto da Psicologia Social, ramo da Psicologia que, no século XX, ocupou-se em buscar dialogar com as Ciências Sociais, também tratando da experiência social adquirida pelos indivíduos que participam de diferentes movimentos sociais. No primeiro contexto, Krech e Crutchfield (1973, p. 13) afirmam que denominações do tipo "homem-que-percebe", "homem-que-necessita" e "homem-que-resolve-problemas" constituem, apenas, uma tripartição que atua como artifício didático para se estudar o homem, ou seja, em psicologia, segundo o autor, "existe apenas um indivíduo - que percebe e luta e pensa", ou seja, que se notabiliza por apresentar um "padrão de percepções, motivos, emoções e comportamento adaptativo" que "não se parece ao de ninguém mais". Neste contexto, o escritor, enquanto indivíduo, é um ser único em destaque na unicidade que conjuga o conjunto humano de indivíduos. Seu mundo é feito do que ele percebe, sente, vê, pensa e imagina como nenhuma outra pessoa pode fazer identicamente. $\mathrm{O}$ mundo, assim percebido, antecede sua criação linguística, fazendo-o, primeiramente, pensar com seus sentidos. Por decorrência, a percepção individual de um escritor é seu pensamento; sua invenção, uma observação acerca do percebido.

Por sua vez, enquanto tipo, o escritor tem sua personalidade levada em consideração, ou seja, tem seus traços, habilidades, crenças, atitudes, valores, motivos, formas de ajustamento e temperamento, seu aspecto externo, o modo 
como é percebido pelos outros, e os influencia, analisados e, muitas vezes, generalizados para "esquemas de compreensão", aqui usando uma expressão de Eduard Spranger (1928). Os traços estão na pessoa; os tipos, em um ponto de vista externo. Assim, temos, de acordo com as particularidades de cada classificação, filistinos versus boêmios; apolíneos versus dionisíacos; racionalistas versus empiricistas, por exemplo. Spranger, focando analisar valores humanos fundamentais, admite como tipos o teórico, o estético, o social, o político e o religioso. Não que uma pessoa pertença totalmente a um desses tipos, mas, sim, que podemos compreender uma pessoa examinando, através dessas denominações, os seus valores.

Cumpre ressaltar que, enquanto abstrações criadas para alimentar tais esquemas de compreensão, nenhuma tipologia explica o indivíduo total. Há autores que defendem o emprego de tipos ideais (derivados de métodos racionais, como os de Spranger), bem como, os que defendem o emprego de tipos empíricos (que supõem abranger uma grande área de personalidade de muitas pessoas, extremos de um contínuo, como, por exemplo, introvertidos versus extrovertidos); tipos culturais (influenciados por sua participação em grupos, sejam típicos ou dissidentes destes, como, por exemplo, um comerciante, um fazendeiro, um barbeiro, um padre, um político, etc) e tipos propedêuticos (que introduzem conhecimentos básicos sobre um assunto, como, por exemplo, tipos constitucionais, perceptuais, cognitivos, de maturidade, de imaturidade etc). Entretanto, embora tipo, integrando um grupo social, uma personalidade é regulada por traços, ou seja, por sua personalidade atuante, que reside no interior de si, e não em sua profissão.

Allport (1969, pp. 35-36), ao abordar a questão dos tipos, em Psicologia, esclarece que essa "é uma abordagem parcial da individualidade", que busca, muitas vezes, a generalidade e a amplitude, ou seja, possibilitar a classificação de um tipo como uma pessoa "liberal, ou narcisista, ou cerebrotônica, autoritária”, entre outras, com a finalidade de encontrar "uma categorização ampla e válida dos seres humanos". Porém, ainda segundo o autor (p. 438), "a partir de tipos, os pesquisadores, muitas vezes, chegam a informações úteis a respeito de traços complexos, e nada mais do que isso".

\section{O Estudo do Processo de Criação}

Em Houaiss e Villar (2001, p. 868), o verbete "criação" é reconhecido, entre outros sentidos, como o processo, ou efeito, de conceber, inventar e gerar, por intermédio da ação humana, divina ou de similar força superior, o que não existe, bem como, de dar nova forma, novo uso e aperfeiçoamento ao que já tem existência. Produto intelectual, por excelência, uma vez que reclama exercício do raciocínio e das habilidades para executar complexidades, a criação valhe-se, segundo Sartre (1996, p. 150) de consciências imaginantes que, unidas em sequência lógica, "produzirá para o objeto enquanto imagem uma espécie de vida", aparecendo num aspecto ou em outro de acordo com o que o homem percebe através dos sentidos:

Julgar que um cocheiro cujo rosto representamos obscuramente tenha bigodes é ver aparecer seu rosto com bigodes... Se, no modo imaginante, pensamos em objetos individuais, serão esses mesmos objetos que irão aparecer à nossa consciência... Na verdade, é raro que pensemos numa classe isolada. A maior parte do tempo, nossos pensamentos são estabelecimentos de relações entre classes. (Sartre, 1996, pp. 150-151)

Na concepção sartriana, portanto, as descrições de tipos, ambientes, sensações e emoções verificáveis em textos literários nos colocam diante de um sistema simbólico cuja compreensão é um movimento que nunca se conclui, mas no qual as simbologias se buscam continuamente para o progresso do conhecimento. Entretanto, esse imaginário concebido pelo senso comum difere do imaginário coletivo, no qual é a subjetividade da pessoa que se apresenta ao inconsciente, e do imaginário pessoal, em que as imagens de um povo e de uma cultura é que são apresentadas ao leitor. Por sua vez, o acervo de subjetividades e imagens culturais de um povo é concebido por Durand (2001) como uma resposta à angústia humana diante da finitude da vida, ou seja, o homem necessita delinear um trajeto 
antropológico que lhe reafirme, constantemente, sua capacidade de criar realidades e percebê-las.

Do E-Dicionário de Carlos Ceia (s.d.), temos que o verbete imaginação é derivado do latim imaginatio, que por sua vez substitui o grego phantasía. Segundo Ceia, a imaginação, já no aristotélico De Anima (428a 1-4), resume-se ao processo mental através do qual concebemos uma imagem (phantasma), uma vez que, para Aristóteles (trad. 2006), a mente humana não é capaz de pensar sem imagens, com ela representando o que não existe no nosso mundo imediato. O sentido original grego do conceito, mantido em alemão (Phantasie), esclarece Ceia, é o que está presente nos primeiros grandes teóricos do inconsciente, Freud e Jung, ou seja, é como estes sempre a utilizaram. Por sua vez, os estudos literários do século XVIII realçaram o poder criador da imaginação como atividade essencial da criação artística, clara oposição ao que significava imaginar na Antiguidade, a saber, um exercício irmanado a sentimentos de melancolia, nostalgia, saudade, medo e tédio. Esta dependência de necessitar sentir para poder imaginar representará para Platão não uma forma de alcançar o conhecimento, mas, sim, de obter uma espécie de cópia em segunda mão da realidade. Argumento, este, retomado por Descartes (1986, pp. 31-32), no Discurso do Método, por ocasião de o filósofo afirmar que "nem a imaginação nem os sentidos poderiam nunca nos certificar de qualquer coisa sem a intervenção do entendimento".

Com o romantismo europeu, que creditou à imaginação o status de alternativa subjetiva para se alcançar formas de conhecimento menos pragmáticas, e os questionamentos kantianos, que admitiram a imaginação como síntese das percepções humanas, às quais são propostas imagens que a representem, uma nova teoria da imaginação se estabelece, propondo-a como caminho privilegiado para o conhecimento subjetivo, em detrimento do pragmático. Neste contexto, Coleridge, um dos criadores do romantismo na Inglaterra, admitindo que só através da imaginação é possível experimentar toda a vitalidade dos sentidos, eleva a mesma ao poder criador de Deus; opinião compartilhada pelo filósofo ale- mão Schlegel, que entende a imaginação como capacidade de associação de imagens ao nível da consciência, contrária à fantasia, que operaria com imagens surgidas na fronteira com o inconsciente. $\mathrm{O}$ século $\mathrm{XX}$, entretanto, revelará maior interesse pelo produto originário da imaginação criadora, altamente aproximado a experiências pessoais, do que por sua teorização.

Para o psicólogo alemão Rudolf Arnheim (1974), cabe à imaginação criadora capacitar o homem a traduzir a aparência física de objetos em formas apropriadas a determinados contextos, e isso vem da razão psicológica de que, na percepção e pensamento humanos, a semelhança baseia-se não numa identidade meticulosa, mas na correspondência das características estruturais essenciais. O novo, segundo o autor, só é válido, entretanto, até onde serve para interpretar um universal tópico da experiência humana. Recorrendo a obras de arte para exemplificar as propriedades do que pode ser percebido pelo homem através da visão, o behaviorista Arnheim (1974) concebe que, uma vez dinâmica e não estática, a imagem não constitui arranjos, mas, sim, interações de tensões próprias, direcionando para o raciocínio de que não é o olho que constrói a interação dos objetos em um campo visual, mas, sim, que é a dinâmica das formas que determina o modo como esse campo visual é percebido. Vem dai que, definir a obra de arte como uma forma expressiva criada para nossa percepção através dos sentidos ou imaginação, expressando o sentimento humano, como fez Susan Langer (1957), é altamente aceitável no horizonte dos estudos literários.

Do processo criador em literatura, Wellek e Warren (1949) admitem que estudos modernos acercar-se-iam do papel relativo desempenhado pelo consciente e inconsciente, uma vez que o literato é especialista em associação (engenho), dissociação (juízo) e recombinação (fazer um novo todo a partir de elementos experimentados separadamente) de palavras, para ele símbolos valiosos em si mesmo e pelo que representam. Neste caso, supor que a criação de personagens consiste numa fusão de tipos herdados, tipos obervados e do tipo encarnado pelo próprio autor sinaliza para o fato de somente 
$\mathrm{o}(\mathrm{s})$ "eu(s)" reconhecido(s) como matéria potencial para a criação literária poderá(ão) tornar-se personagem(ens) complexa(s). Não obstante, a psicologia pode estudar, também, os diversos métodos de composição, correção e reescritura praticados por literatos. A utilidade disso? Descobrir-lhe brechas que permitam sondar o que ocorre em seu laboratório de produção artística que coíba inconsistências e distorções na obra de arte a qual se propõem a criar; mas, sempre atentos que, a despeito de serem práticas da criação, estas não pertencem à obra de arte; antes, a sua elaboração.

Certamente, é possível afirmar que personagens ficcionais se apresentam psicologicamente verdadeiras, principalmente nos casos em que o autor buscou na psicologia as figuras e relações interpessoais que utilizou na sua obra de arte. Mas tais características se sobrepõem tão constantemente que são as situações complexas em que se envolvem, e nas quais atuam, que merecem observações mais agudas que a possibilidade de encaixa-las num tipo social específico. Exemplo disso são obras construídas pela técnica do fluxo de consciência. Nelas, a reprodução fidedigna dos processos mentais apresentados é menos relevante que a possibilidade de dramatização oferecida pela técnica utilizada. Ou seja, não é a verdade psicológica, independente de realçar a noção de realidade da criação, que dará valor artístico à obra de arte, mas, sim, como ela foi manipulada para realçar a coerência e a complexidade e, assim, se obter algo realmente novo.

\section{O Estudo dos Tipos e das Leis que estão Presentes nas Obras Literárias}

O Estudo dos Tipos. Nos estudos literários, o tipo é estudado como uma das possibilidades de personagem a ser criada. Configuração esquemática, tanto no sentido físico como no psíquico, projetada como um indivíduo "real", totalmente determinado, bem como, um dos três elementos estruturais essenciais do romance, o tipo, em Forster (1974), é uma das caracterizações das personagens planas, lineares, definida por um único traço, imutável ao longo de toda obra. Prática comum no romance histórico, a presença do tipo, segundo Kaufman (1991), se justifica pela necessidade de existir representantes de um dado meio ou classe social em cujos destinos ficcionais se refletiriam tendências importantes e mudanças históricas.

Representando a sociedade ou um grupo social específico, tem sua construção literária possibilitada, entre outros aspectos, graças à atenção que o autor confere à significação de suas palavras, bem como, à prática da oralidade que a mesma estabelece entre locutores e interlocutores na trama textual, o que lhes garante a representação linguística e imagética importantes para inseri-las no universo de determinada época. Planas, seu papel vincula-se a uma situação especifica ou a uma conduta generalizada, característica esta que também as distanciam da caricatura, distinguida, esta última, por apresentar uma qualidade ou ideia única levada ao extremo, de forma a tal distorção conclamar a sátira propositadamente. Identificadas, portanto, pela profissão, comportamento e classe social, ou seja, por um traço distintivo comum a todos os indivíduos de uma mesma categoria, seria, por exemplo, o homem bom, defensor dos valores sociais; o homem mal, defensor das vilanias; o ancião, aquele que sabe dar conselhos, entre outros, todos possuindo em comum uma competência interiorizada.

O Estudo das Leis. Certamente é possível utilizar a psicologia para lançar luz à interpretação e valoração de obras literárias, assim como, é possível proceder da mesma forma em relação à sociologia, à filosofia, à história e outras disciplinas mais que, apoiadas em seus construtos teóricos, podem auxiliar o leitor na compreensão de conceitos fundamentais sobre os quais um enredo literário possa ter sido elaborado. Mario Valdés (2004), favorável à existência de um campo limitado de interpretações num ponto dado da narrativa, entende que a interpretação mediatizada pela diversidade de campos de conhecimento deve destacar o sentido do texto e comunicar esse sentido em relação a outros, transpondo-o do domínio subjetivo ao domínio do intersubjetivo. É atraindo uma linguagem adequada à sua produção de sentido, que a obra literária, na medida em que, exercitando o princípio da síntese, 
afirma uma linguagem comunicável, capacita-se a ser mimética.

Jean Bessière, estudioso francês do fato literário (1995), reconhece existir na literatura, independentemente do gênero e forma por ela adotados, a aptidão para a representação de um conteúdo indissociável do mundo e da história, bem como, de seus respectivos correspondentes no mundo das referências imaginárias. Entretanto, Wellek e Warren (1949) alertam para os perigos de se direcionar interesse investigativo a rascunhos, versões rejeitadas, exclusões e outros cortes originais efetuados por autores: a despeito da compreensão estilística que poderemos vir a ter de seu autor, os mesmos já não pertencem à obra de arte que se analisa, não valorizam o que há de concreto no que foi literariamente criado.

Específico para tratar de qual/quais critério/ critérios faz/em com que algo seja considerado literatura, o termo literariedade, definido como discurso fictício ou imitação dos atos de linguagem cotidianos, assim como, em relação a certas propriedades da linguagem (Culler, 1995), apresenta, teórica e metodologicamente, relevantes aspectos do objeto literário. Representando o real ou se auto-representando, uma obra literária pode apresentar intenções realistas, na qual a personagem é identificada como indivíduo social; intenções semânticas convencionais, nas quais o narrado faz a mediação de instâncias que acontecem na narrativa; intenções de simulação, nas quais o dizível e o indizível são sempre indiretos; e intenções de simbolização social, na qual a narrativa compreende uma retomada da maneira como a sociedade se simboliza a si própria.

Segundo Proença (2001), a relação literatura e especificidade, bem como, questões envolvendo a complexidade, a multissignificação, o predomínio da conotação, a liberdade na criação, a ênfase no significante e a variabilidade, por exemplo, são características do discurso literário que orientam, de modo peculiar, tal universo de estudo, respondendo, enquanto regras, pelos modos de realização da literatura enquanto prosa e enquanto verso. Tal apresentação de fundamentos para uma teoria da produção artística, entretanto, merecendo uma discussão específica, como a realizada por Bordieu (1996), que excede as expectativas deste trabalho.

O Estudo dos Efeitos da Literatura sobre os Leitores. Wolfgang Iser (1996), na obra "O Ato da Leitura", publicada, originalmente, em 1976, fez da interação entre leitor e texto um grande estudo acerca de como, e sob quais condições, um texto tem significado para o leitor. Uma vez que a interpretação tradicional tinha visão para elucidar significados ocultos, Iser queria ver o significado como resultado de uma interação entre texto e leitor, como um efeito que é sentido pelo leitor e não uma mensagem que precisa ser encontrada no texto. Em outras palavras, para Iser, os textos, de um modo geral, trazem enunciados que podem ser compreendidos pelo leitor, mesclados com outros enunciados que exigem do leitor uma complementação de sentido, um preenchimento de seus "vazios", ou seja, do que eles não relatam explicitamente. Essa complementação atuante do leitor faz com que este, a todo instante, se questione se a formulação de sentido que está fazendo é a adequada à leitura que está cumprindo. E é mediante esta condição que ocorre a interação do texto com o leitor, o que é bem diferente de ler o texto em busca de uma mensagem oculta, ou de uma interpretação única.

Roman Ingarden (1979) forneceu uma útil explicação para esta investigação. De acordo com Ingarden o objeto estético é constituído apenas através do ato de cognição do leitor. Adotando este preceito de Ingarden, Iser (1979) assim troca o foco do texto como um objeto para o texto em potencial, nascido dos resultados do ato da leitura. Para examinar a interação entre o texto e o leitor, Iser olha aquelas qualidades no texto que o fazem legível, merecedor de ser lido ou que influenciam nossa leitura, e aquelas características do processo de leitura essenciais para a compreensão do texto. Particularmente, neste trabalho inicial, ele adota o termo "leitor implícito" para abranger ambas as funções. Este está na estrutura do ato e na estrutura textual. Mais tarde, dependendo mais profundamente da terminologia de Ingarden, ele diferencia texto, concretização do texto e trabalho de arte. $\mathrm{O}$ 
primeiro diferenciador entre o texto e o trabalho de arte é o aspecto artístico, que é localizado ali pelo autor para nós o lermos, e ele precisa ser melhor concebido como uma potencial realização esperada. A concretização do texto, por contraste, refere-se ao produto de nossa própria atividade produtiva; ela é a realização do texto no pensamento do leitor, alcançada pelo preenchimento do que está em branco ou aberto para eliminar o indeterminado.

Finalmente, a obra de arte não é texto nem concretização, mas algo entre ambos. Ela ocorre no ponto de convergência entre o texto e o leitor, um ponto no qual nada nunca está completamente definido. A obra de arte é caracterizada pela sua natureza virtual e é constituída por vários procedimentos sobrepostos. Um destes envolve a dialética da protensão e retenção, dois termos emprestados da teoria fenomenológica de Husserl (1986). Por protensão entenda-se o estado de expectativa que prepara a reprodução da lembrança, ou seja, é a pré-lembrança. Por retensão entenda-se a lembrança primária que o texto lido nos traz. É através de protenção e retensão que os textos se duplicam, deslocando-se dos textos originais para novas obras do presente. Iser (1979) os aplica para nossa atividade de ler sucessivas sentenças. Defrontando-nos com um texto, nós, continuamente, projetamos expectativas as quais podem ser satisfeitas ou desapontadas; ao mesmo tempo nossa leitura é condicionada pela renúncia de sentenças e concretizações. Pelo fato de nossa leitura estar determinada por esta dialética, a atividade básica do leitor, segundo Iser, reside na constituição de sentido, estimulada pelo texto. Com este sentido realizando-se através da conexão dos elementos constitutivos do texto, bem como de suas articulações e combinações responsáveis pela coerência e coesão do mesmo. Para Iser é através do preenchimento dos vazios e dos brancos de um texto que o leitor chega ao sentido do mesmo. Entenda-se por vazios e brancos tudo o que não foi dito explicitamente no texto e sim sugerido de modo tácito. Esse envolvimento com o texto é visto como um tipo de emaranhado no qual o estranho é compreendido e assimilado. O ponto de vista de Iser é que a atividade do leitor é similar a uma experiência atual.

De acordo com Iser (1979), pelo preenchimento dos "vazios", ou seja, a partir dos sentidos que vamos atribuindo ao que lemos, nós, simultaneamente, nos reconstruímos a nós mesmos, desde que nosso encontro com a literatura seja parte de um processo de compreender o outro e nós mesmos mais completamente:

"À medida que os vazios indicam uma relação potencial, liberam o espaço das posições denotadas pelo texto para os atos de projeção... do leitor. Assim, quando tal relação se realiza, os vazios desaparecem" (Iser, 1979, p. 106).

Contudo, Iser (1976/1996) não descarta a possibilidade de fracasso na comunicação e no diálogo, ou seja, se o equilíbrio se torna possível com o preenchimento dos vazios pelas projeções do leitor, esta mesma interação pode fracassar se as projeções do leitor se impõem, independentemente do texto. Logo, para Iser (1976/1996), a atividade básica do leitor reside na constituição de sentido, estimulada pelo texto, que advém da conexão dos seus elementos constitutivos, das articulações e da necessidade de combinação, responsável pela coesão do texto, através do preenchimento de seus vazios, e de seus brancos. Os vazios quebram ainda a "good continuation", ou seja, continuação desejável, provocando o reforço da atividade de composição do leitor. É preciso que o leitor recorra à sua atividade imaginativa para estabelecer a coerência significativa do texto.

Constituído deste modo, o horizonte de expectativas do leitor vai sofrendo acréscimos de novas expectativas de leitura através das interpretações que esse mesmo leitor vai fazendo do texto que está a ler. Porém, se esse leitor, baseado em posturas ideológicas que possa vir a ter, recusar tais interpretações textuais, terá dificuldades de identificar o que, em Estética da Recepção, se convencionou chamar de leitor implícito, ou seja, o destinatário que o texto tem por estratégia. Iser (1976/1996) desenvolve, portanto, uma teoria do efeito estético, conduzindo, a partir dos processos de transformação, à constituição do sentido pelo leitor, descreven- 
do a ficção como estrutura de comunicação. $\mathrm{O}$ repertório ficcional, as estratégias textuais, as variantes da leitura, o leitor implícito e os vazios do texto são processos que completam a perspectiva do texto em si mesmo e sua recepção pelo leitor, cujo espaço é garantido nos estudos de seus sucessores críticos.

Entendendo que a obra de arte maior sempre inclui uma visão de mundo que, discutida ou negada, faz parte integrante de seu sentido (2003), Dante Moreira Leite busca apresentar algumas questões da obra literária para as quais a psicologia contemporânea tem uma perspectiva própria, diversa da perspectiva de outras ciências e da própria crítica literária, tais como, a imitação, a sugestão, a percepção de formas, a descrição de personagens, a aprendizagem do gosto, entre outros, sem, no entanto, aspirar a apresentação de solução geral ou total para a análise da mesma. A legitimidade para isso? Segundo o autor (2003), a necessidade de explicar a arte a partir das características do indivíduo, uma vez reconhecida a perda da crença social no sobrenatural, bem como, na determinação hereditária de características individuais e nas explicações sociológicas como origem dessas diferenças, fatos estes ao qual se acresce, a partir do Romantismo, a acentuação da tendência subjetiva nos temas artísticos e no interesse da crítica.

\section{Psicologia na Literatura}

\section{A Psicologia como Perspectiva para a Recepção da Literatura}

Na criação da obra de arte, Leite (2003) entende que o autor ultrapassa aspectos superficiais e aparentes da vida cotidiana, alcançados através de perspectiva histórica e sociológica, em busca do que, expresso acerca da condição psicológica humana, continue válido em situações muito diversas. Neste contexto, contribuições significativas da psicologia contemporânea, tais como, a descrição do comportamento e da experiência interior do indivíduo como atividade espontânea, a continuidade entre os diferentes graus de solução de problemas e de capacidade criadora e a tentativa de interpretar a vida inconsciente através de forças dinâmicas são recursos rele- vantes para esta buscar explicar a criação e a permanência da obra literária.

Todavia, a aplicação de conceitos psicológicos numa análise de obra de arte deve orientar-se pelas possibilidades de explicações que estes apresentem para tal tarefa, ou seja, pela aplicabilidade desses conceitos como recursos ao entendimento do pensamento produtivo, sem que se esqueçam suas limitações. Considerando a relação organismo-ambiente, a relação vida afetiva e vida intelectual e a relação dos processos inconscientes, Leite (2003) pondera conceitos fundamentais da teoria de Freud, Jung e dos gestaltistas, respectivamente, para esclarecer em que medida esses conceitos são úteis para a descrição de processos de pensamento produtivo e/ ou análise de texto e de leitores.

Em Freud, definindo "libido" como vida mental caracterizada pela busca do prazer, do amor (Eros) e afastamento da dor e da morte (Tânatos), bem como, "Id" como a arte mais profunda e primitiva da personalidade e "Ego" como a parte da personalidade em contato com a realidade, Leite (2003) indica estes conceitos como referenciais dos quais se podem partir focalizações para análises literárias entre organismos e ambientes. Neste caso, a permanência de sentimentos ou acontecimentos infantis na vida mental e comportamental do adulto, assim como, a evolução de conflitos emocionais e afetivos em continuidade histórica, com repressão dos instintos proporcional a intensificação neurótica, são aspectos relevantes para abordagem de histórias individuais e histórias culturais, respectivamente.

De modo similar à teoria freudiana, tais manifestações, na literatura, também são apenas "formas diferentes de conflitos iguais", numa civilização em que a "neurose", muitas vezes, é a forma alternativa para expressão de conflitos criadores, os quais, se barrados, enviesam-se por anormalidades e conflitos de expressão. Edgar Allan Poe (1974), por exemplo, adotado, juntamente com os irmãos, por prósperos negociantes em Baltimore, ao manifestar interesse pelo pensamento produtivo em detrimento da lucratividade de negócios, angariou o desgosto do pai adotivo, que o queria um continuador da prospe- 
ridade familiar, crescendo com o sentimento de que era rejeitado como escritor, o que, não poucas vezes, influenciou diretamente sua obsessão pela temática do sofrimento causado pela morte. Por sua vez, Kaufhold (2008), em estudo que analisa o que é fato e o que é fantasia na sanidade de Poe, pontua desordens psicológicas, biológicas e socioculturais humanas, como ansiedade, somatização e dissociação, entre outras, que, encontráveis em todas as culturas, e nos mais diversos tempos, ainda que não assim nomeadas, permitem ao leitor observar serem capazes de uma repressão cada vez maior dos instintos, conhecida de antropólogos e sociólogos nos estudos de processos civilizatórios de ajustamentos.

Entretanto, o fato de a teoria freudiana repousar na interdependência entre vida afetiva ou emocional e vida racional, característica contraditória à crença contemporânea, que supõe continuidade entre ambas, bem como, de racionalizar os problemas apresentados pelo homem em seu ambiente para mostrar a origem emocional e conflituosa dos processos do pensamento humano, desmascara e destrói as ilusões humanas, sejam elas religiosas, sentimentais ou artísticas, fato este que a limita na análise do pensamento criador. No contexto dessa teoria, o conceito de "inconsciente", ligado dinâmica e continuamente à consciência numa relação causa-efeito, e a tentativa freudiana de traduzi-lo para termos inteligíveis, foi considerado uma das contribuições mais significativas que a psicologia concedeu à literatura, principalmente para aqueles que, à semelhança dos românticos alemães, preocupavam-se com "os aspectos noturnos e doentios da personalidade humana". Entretanto, à medida que sua comprovação experimental foi aproximando-se de critérios cada vez mais científicos de verificação, e tornando-se mais aceita pelos cientistas, sua tendência de identificar os mesmos conflitos em todas as obras de arte tornou-a reducionista e menos aceita por escritores e críticos de arte.

Jung, admitindo o conceito freudiano de "libido" como uma espécie de "energia" interna vital ao ser, surge com a proposta de esta poder tomar duas direções inatas, correspondentes às dicotomias subjetivo-objetivo e interno- -externo, que resultariam, respectivamente, na introversão e extroversão do ser. Associado a isso, apresenta, por adição, novos conceitos para descrever o indivíduo, a quem chama de "eu", a saber, "mundo externo"/"mundo interior", "consciência pessoal" (experiência de vida)/“inconsciência coletiva" (experiência ancestral), "arquétipos" (símbolos ou imagens existentes no inconsciente coletivo, que representam as estruturas de todas as coisas que existem), "persona" (parte superficial, desenvolvida como resposta às exigências ambientais), "animus" (alma masculina existente no íntimo de toda mulher), "anima" (alma feminina existente no íntimo de todo homem), "ego" (parte consciente da personalidade, ou seja, nosso 'eu'-'nós'), e "sombra"(qualidades e tendências que, recusadas pelo indivíduo como suas, passam a compor o inconsciente individual).

A valorização do misticismo e da religiosidade e o reconhecimento de forças inconscientes que se projetam no mundo exterior e geram ideias ricas e significativas no pensamento produtivo fizeram da teoria junguiana terreno propício ao desenvolvimento da diversidade das obras de arte, considerado pelos artistas um horizonte mais profundo e revelador que a técnica e o conhecimento do mundo externo proporcionados pelo freudismo. Em Capitães da Areia, de Jorge Amado (1944), obra que narra a história de um grupo de meninos abandonados, e entregues à própria sorte, na cidade de Salvador, cada um dos integrantes do grupo detém uma identidade altamente simbólica, diretamente proporcional à noção junguiana de arquétipo, a saber, as dicotomias inocência/perversidade, heroísmo da "criança-herói"/divindade da "criança-deus", proteção/abandono, fragilidade/invencibilidade, passado/futuro, entre outros, adicionáveis às suas considerações sobre as quatro funções intelectuais, distinguidas como pensamento, sentimento, percepção e intuição, caracterizáveis de acordo com seu aparecimento em introvertidos e extrovertidos.

Por sua vez, voltados para os estudos perceptuais, os gestaltistas, admitindo o comportamento como resultante da interação organismo-ambiente, optam por trabalhar com campos de 
força atuantes em várias direções, capazes de organizar-se e reorganizar-se continuamente, alternando estados de repouso (organizados) e estados de busca (reorganizados) para o alcance de um objetivo, o qual, cessado, redireciona o sujeito a voltar-se para novas focalizações. A vantagem desse tipo de análise? A partir de sucessivos estados de equilíbrio e desequilíbrio, o analista conseguir estudar o organismo exatamente em um determinado momento, só se preocupando com a história desse organismo caso ela seja identificada como força atuante no momento considerado.

$\mathrm{O}$ que diferencia os gestaltistas de Freud e Jung? A oposição do modelo da mecânica, baseado em "energia", destes dois últimos, para com o modelo da eletricidade, baseado em "campos de força", dos primeiros, bem como, os gestaltistas, ao contrário dos psicanalistas, acentuarem mais as características dos objetos que as dos indivíduos, estudando casos em que o comportamento é dirigido pelo ambiente e não pelos impulsos do organismo, sem, entretanto, isolar comportamento e experiência, o que inviabilizaria tal estudo. Ou seja, segundo Leite (2003, p. 36), enquanto Freud e Jung "supõem o homem como um ser impulsionado por forças inconscientes, de caráter afetivo", para os gestaltistas "o comportamento parece determinado, fundamentalmente, pelo contacto 'inteligente' com o ambiente", o que leva a:

os psicanalistas procuram descobrir ou revelar os aspectos irracionais subjacentes ao comportamento aparentemente racional, enquanto os gestaltistas procuram descobrir, mesmo no comportamento emocional, características de racionalidade ou percepção adequada (Leite, 2003, p. 37).

Tal diferença ficando mais explícita por ocasião da análise do pensamento produtivo em literatura, quando os psicanalistas conseguem fazê-lo na arte, mas não na ciência e na técnica, bem como, quando os gestaltistas, ao contrário, explicam o pensamento criador na ciência, mas, ao focar a arte, acentuam aspectos ligados à percepção, e não à arte literária. O responsável por isso? O fato de os gestaltistas, contrariamente aos psicanalistas, não terem reservado um lugar, entendido como reservatório de energia, para o inconsciente.

Por fim, ainda que um grupo de psicólogos, entre os quais, o psicólogo alemão Hans Jürgen Eysenck, acreditando que a singularidade da personalidade fosse igual a de outros objetos, e que a descrição de um indivíduo não passasse de uma peculiar combinação de características comuns a todos, negasse a necessidade de uma teoria da personalidade, esta surgiu, acentuando ser a singularidade do indivíduo, ou seja, o que o faz distinguir-se de qualquer outro modo de ser humano que não seja o seu, que permite, entre outros, a discussão de questões ainda em discussão na contemporaneidade, como, por exemplo, de a personalidade existir "no" indivíduo versus em algo que, num determinado momento, o analista consiga descrever, bem como, de ser estável no tempo e no espaço. No primeiro caso, enquanto para uns a "unidade' do indivíduo é algo a se buscar, para outros, vários sistemas personalísticos podem existir, desde que suas descrições sejam úteis cientificamente. No segundo, colocada a relação organismo-ambiente em seu extremo, o conceito personalidade orientaria a concepção de que esta, enquanto conjunto de características individuais, independe do contexto em que o indivíduo está inserido.

De modo geral, Leite (2003) esclarece que, com exceção das personalidades patológicas, encerradas em seus próprios mundos, e dos despersonalizados, que refletem as condições em que se encontram, eliminar a importância do contexto na personalidade, ocasiona uma focalização redutora da mesma, que desconsidera, por exemplo, indivíduos capazes de ajustar-se, ou reagir de modo realista, sem serem alterados pela realidade do ambiente ao qual se inserem, existem. Também (Leite, 2003, p. 39), que personalidade é conceito que concebe "uma unidade que se manifesta em todos os aspectos do comportamento e da experiência de um indivíduo... e que nos permite identificar e descrever uma pessoa, entre todas as outras". O aperfeiçoamento das descrições de personalidade, segundo Leite, ocorre, muitas vezes, em descrições literárias ou de pes- 
soas que, ainda não descritas por especialistas da psicologia, em muito acrescem valor e conteúdo aos estudos destes últimos. Contemporaneamente, a hereditariedade tem sido sobreposta à experiência passada ou momentânea, fazendo com que o comportamento seja entendido como resultante da interação com o ambiente. Skinner e Watson, psicólogos comportamentistas, que tendem a explicar todo o comportamento através da aprendizagem, sendo exemplos disso.

Considerando que o comportamento resulta dessa interação organismo-ambiente, Leite entende que a psicologia atual deve ter, portanto, recursos para explicar duas formas de comportamento que interessam diretamente à literatura, que são, o pensamento criador e a leitura de obra literária. Examinar a adequação da psicologia para explicar esses dois comportamentos é lançar luz sobre como se realiza, e concretiza, a tentativa de tanto o psicólogo quanto o ficcionista apresentar a descrição convincente de uma pessoa e de um personagem.

\section{O Processo Criador: Recepção e Resposta ao Meio}

De acordo com Dante Moreira Leite (2003), a psicologia tradicional entendia o comportamento humano como algo resultante da vida mental. Neste contexto, haveria uma relação causal entre consciência e comportamento, ou seja, o comportamento era determinado pelo que o homem pensava. Entretanto, a psicologia contemporânea entende que a consciência deve ser entendida como um elo intermediário entre ambiente e comportamento, ou seja, que o homem sofre influência do ambiente e de suas próprias idiossincrasias para emitir uma resposta ao meio. Assim sendo, várias teorias psicológicas empregam esquemas diferentes para explicar o comportamento. Dentre essas teorias psicológicas, a mais simples seria a teoria comportamental, a qual supõe que o comportamento, ou seja, a resposta, resulta do ambiente, ou seja de estímulos, e tem como modelo de explicação o reflexo condicionado, por meio do qual se dá o encadeamento de estímulos e respostas. Esta teoria é identificada pelo modelo E-R, ou seja, teoria do estímulo-resposta. Sendo o comportamento resultado dessa interação organismo-ambiente, Leite entende que a psicologia atual deve ter recursos para explicar duas formas de comportamento que interessam diretamente à Literatura, a saber, o pensamento criador e a leitura de obra literária. Uma vez que a este trabalho interessa o comportamento que advém da leitura da obra literária, tentaremos, nas linhas abaixo, relacionar um esquema da teoria E-R ao estudo por nós aqui proposto.

Considerando o que foi dito, até o momento, sobre texto, leitor e expectativa, entendemos ser possível generalizar, respectivamente, um modelo estímulo, organismo e resposta, no qual o texto corresponderia ao estímulo (E), o leitor ao organismo $(\mathrm{O})$ e a expectativa à resposta $(\mathrm{R}), \mathrm{o}$ qual é comumente aplicável em Psicologia e que poderia explicar o pensamento criador e a leitura de obra literária como sendo duas formas de comportamento e experiência, respectivamente. Assim sendo, teríamos o seguinte esquema:

$\mathrm{O}$ esquema acima apresentado se refere à percepção, ou seja, ao processo no qual o leitor se encontra sujeito tanto aos estímulos, representado pelas propriedades do livro, quanto às suas próprias características de percebedor, representadas pelas propriedades do leitor. Considerado desta forma, este esquema permite compreender que a mesma obra pode ser percebida em vários níveis, com diferentes intensidades e, principalmente, susceptível às idiossincrasias do leitor. Guiando-nos pelos estudos de Rozestraten (1988), e transpondo-os, na medida do possível, ao estudo do papel do leitor na literatura, temos que, para que se produza uma leitura adequada de determinada obra, são necessárias pelo menos três condições: a presença de estímulos ou de situações (indicados por E) que possam ser observadas e percebidas: o livro; um organismo em condições de perceber e de reagir adequadamente aos estímulos percebidos (indicado por O): o leitor; uma resposta aos estímulos que identifiquem como o organismo se comporta no sistema de leitura: a opinião.

Interados entre si os elementos deste esquema, entendemos serem os mesmos válidos para representarem, esquematicamente, o processo de 
Texto - Leitor - Expectativa

ou

$\mathbf{E}-\mathbf{O}-\mathbf{R}$
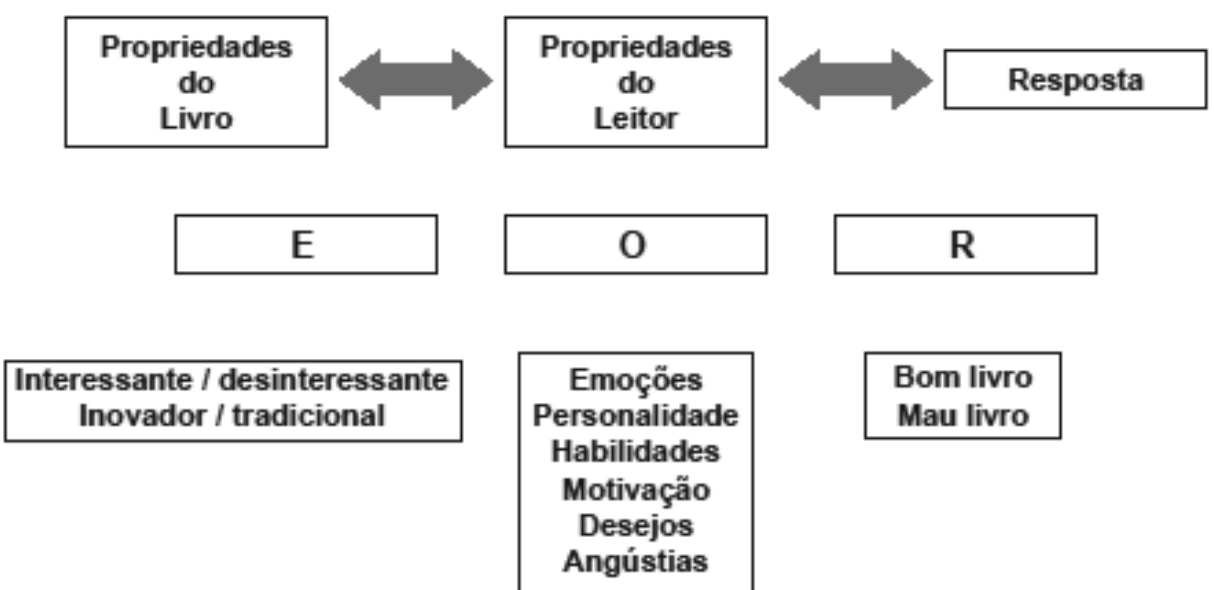

Bom livro

Mau livro

Figura 1. Texto - Leitor - Expectativa ou E (Estímulo) - O (Organismo) - R (Resposta).

recepção textual. Cumpre lembrar, no entanto, que não é só o estímulo que provoca e determina a resposta do crítico, mas que esta também é influenciada pelo organismo com toda a sua experiência e aprendizagem anterior, ou seja, existem as experiências subjetivas de toda uma vida, tudo se manifestando no leitor. Ciclo contínuo, sua divisão em etapas serve, apenas, para clarificar seus eventos mais importantes, bem como para tornar a explicação do processo de leitura a mais didática possível. Toda interpretação é, apenas, uma forma de revelar aspectos de determinada obra, sempre permanece aquém do conteúdo total da mesma.

Por sua vez, focalizações específicas ao processo criador, ou seja, desvinculadas da recepção do mesmo, podem ser realizadas, segundo Willemart (2009), em materiais que cercam os grandes escritores, como, por exemplo, na tradição por eles respeitada, na escola que frequentaram, na época vivida, em suas ideologias, preconceitos e mediocridade humana, os quais, em constante busca pelo inédito, tornam a escritura de literatura porta-voz de uma reconstrução identitária na qual cada rasura resolvida é (re)construção progressiva da identidade autoral e de sua obra.

\section{Referências}

Allport, G. W. (1969). Personalidade: Padrões e desenvolvimento. São Paulo, SP: Herder.

Amado, J. (1944). Capitães da Areia. São Paulo, SP: Livraria Martins.

Arnheim, R. (1974). Arte e percepção visual. São Paulo, SP: Edusp.

Bessière, J. (1995). Literatura e Representação. In M. Angenot, Teoria Literária: Problemas e perspectivas (pp. 379-396). Lisboa: Publicações Dom Quixote.

Bordieu, P. (1996). As regras da arte: Gênese e estrutura do campo literário. São Paulo, SP: Companhia das Letras.

Ceia, C. (s.d.). Imaginação. Recuperado em http:// www.edtl.com.pt/?option $=$ com mtree $\&$ task $=$ viewlink\&link_id=412\&Itemid $=2$

Culler, J. (1995). O que é literariedade. In M. Angenot, Teoria Literária: Problemas e perspectivas (pp. 45-47). Lisboa: Publicações Dom Quixote.

Descartes, R. (1986). Discurso do método. Lisboa: Livraria Sá da Costa.

Durand, G. (2001). As estruturas antropológicas do imaginário: Introdução a arquetipologia. São Paulo, SP: Martins Fontes. 
Forster, E. M. (1974). Aspectos do romance. Porto Alegre, RS: Globo.

Houaiss, A., \& Villar, M. de S. (2001). Dicionário Houaiss da Língua Portuguesa. Rio de Janeiro, RJ: Objetiva.

Husserl, E. (1986). A Ideia da Fenomenologia. Lisboa: Edições 70 .

Ingarden, R. (1979). A Obra de Arte Literária (2. ed.). Lisboa: Fundação Calouste Gulbenkian.

Iser, W. (1979). A interação do texto com o leitor. In H. R. Jaus, A literatura e o leitor: Textos de Estética da Recepção (L. C. Lima, Trad.). Rio de Janeiro, RJ: Paz e Terra.

Iser, W. (1996). O ato da leitura: Uma teoria do efeito estético (Vols. 1-2). São Paulo, SP: Editora 34. (Original publicado em 1976)

Kaufhold, J. A. (2008). The neuroses of Edgar Allan Poe: A fever called living. New York: iUniverse.

Kaufman, H. (1991). A metaficção historiográfica de José Saramago. Colóquio / Letras, 120, 124 136. Recuperado em http://coloquio.gulbenkian. $\mathrm{pt} / \mathrm{bib} /$ sirius.exe/issueContentDisplay? $\mathrm{n}=120 \& \mathrm{p}$ $=124 \& \mathrm{o}=\mathrm{p}$

Krech, D., \& Crutchfield, R. (1973). Elementos de Psicologia (Vols. 1-2). São Paulo, SP: Pioneira.

Langer, S. (1957). Problems of Art: Ten Philosophical Lectures. New York: Scribner's Sons.

Leite, D. M. (2003). A psicologia e o estudo da literatura In D. M. Leite, Psicologia e Literatura. São Paulo, SP: Editora da Universidade Estadual Paulista.

Poe, E. A. (1974). Biblioteca Universal Estados Unidos - Contos. São Paulo, SP: Três.
Pombo, O. (2005) Interdisciplinaridade e interação dos saberes. Liinc em Revista, 1(1), 3 -15.

Proença, D., Filho. (2001). A linguagem literária. São Paulo, SP: Ática.

Rozestraten, R. J. A. (1988). Processos psicológicos básicos do comportamento no trânsito. In R. J. A. Rozestraten, A. Psicologia do trânsito: Conceitos e processos básicos. São Paulo, SP: E.P.U.

Russell, D. H. (1964). Psychology and literature. College English, 25(7), 551-553. Retrieved from http://www.jstor.org/stable/373246

Sartre, J.-P. (1996). O imaginário: Psicologia fenomenológica da imaginação. São Paulo, SP: Ática.

Spranger, E. (1928). Types of men: The psychology and ethics of personality. Halle, Germany: Niemeyer.

Valdés, M. (2004). Literary Cultures of Latin America: A Comparative History: Configurations of literary culture. Oxford, UK: Oxford University Press.

Wellek, R., \& Warren, A. (1949). Teoria da Literatura. Mira-Sintra, Portugal: Publicações Europa-América.

Willemart, P. (2009). Os processos de criação na escritura, na arte e na psicanálise. São Paulo, SP: Perspectiva.

Recebido: 12/12/2016

$1^{a}$ revisão: $14 / 01 / 2017$

$2^{a}$ revisão: $15 / 05 / 2017$

Aceite final: $17 / 05 / 2017$ restrições em qualquer meio, desde que você dê crédito apropriado ao(s) autor(es) original(ais) e à fonte, fornecer um link para a licença Creative Commons e indicar se as alterações foram feitas. 